\title{
The product of the yeast UPF1 gene is required for rapid turnover of mRNAs containing a premature translational termination codon
}

\author{
Peter Leeds, ${ }^{1}$ Stuart W. Peltz, ${ }^{2}$ Allan Jacobson, ${ }^{2}$ and Michael R. Culbertson ${ }^{1,3}$ \\ ${ }^{1}$ Laboratories of Genetics and Molecular Biology, University of Wisconsin, Madison, Wisconsin 53706 USA; ${ }^{2}$ Department of \\ Molecular Genetics and Microbiology, University of Massachusetts Medical School, Worcester, Massachusetts 01655 USA
}

mRNA decay rates often increase when translation is terminated prematurely due to a frameshift or nonsense mutation. We have identified a yeast gene, UPF1, that codes for a trans-acting factor whose function is necessary for enhanced turnover of mRNAs containing a premature stop codon. In the absence of UPF1 function, frameshift or nonsense mutations in the HIS4 or LEU2 genes that normally cause rapid mRNA decay fail to have this effect. Instead, the mRNAs decay at rates similar to the corresponding wild-type mRNAs. The stabilization of frameshift or nonsense mRNAs observed in upf1 ${ }^{-}$strains does not appear to result from enhanced readthrough of the termination signal. Loss of UPF1 function has no effect on the accumulation or stability of $\mathrm{HIS4}^{+}$or $\mathrm{LEU} 2^{+}$mRNA, suggesting that the UPF1 product functions only in response to a premature termination signal. When we examined the accumulation and stability of other wild-type mRNAs in the presence or absence of UPF1, including MATa1, STE3, ACT1, PGK1, PAB1, and URA3 mRNAs, only the URA3 transcript was affected. On the basis of these and other results, the UPF1 product appears to participate in a previously uncharacterized pathway leading to the degradation of a limited class of yeast transcripts.

[Key Words: Saccharomyces cerevisiae; UPF1 gene; mRNA stability; premature stop codon]

Received August 8, 1991; revised version accepted September 24, 1991.

Nonsense mutations that generate a premature translational termination signal often reduce the steady-state accumulation of the corresponding mRNA (Brown 1989; Peltz et al. 1990). In a study of the yeast URA3 gene, it was shown that the extent of reduced mRNA accumulation depends on the position of the nonsense mutation (Losson and Lacroute 1979). Mutations near the 5' end of the transcript were shown to have a greater destabilizing effect than mutations near the $3^{\prime}$ end. Furthermore, introduction of an amber tRNA suppressor restabilized ura3 nonsense mRNA, indicating that the turnover rate is determined in part by the relative efficiencies of termination versus readthrough of the stop codon. These studies suggested that the turnover rate of nonsense mRNA is probably related to some aspect of its translation rather than to a potential change in mRNA structure that might result from the presence of a nonsense mutation.

Similar studies in higher eukaryotes have proven more difficult to interpret. In some cases, the introduction of a premature stop codon into a gene has been linked to

${ }^{3}$ Corresponding author. increased cytoplasmic turnover (Maquat et al. 1981; Barker and Beemon 1991). However, other studies suggest that nonsense mutations may cause changes in nuclear processing and/or transport, and these changes, rather than cytoplasmic mRNA degradation, may be primarily responsible for decreased steady-state mRNA levels (Humphries et al. 1984; Takeshita et al. 1984; Urlaub et al. 1989; Cheng et al. 1990).

Here, we report the characterization of mutations in the yeast Saccharomyces cerevisiae that specifically stabilize mRNAs containing a premature translational termination signal. The mutations arose in a strain containing his4-38, a + 1 frameshift mutation near the 5 ' end of the HIS 4 transcript that causes translational termination at an adjacent downstream stop codon (Donahue et al. 1981). In this study we show that the his4-38 mutation results in a four- to fivefold decrease in mRNA stability.

In addition to his4-38, the strain used to select mutants also contained SUF1-1, which codes for a glycine tRNA frameshift suppressor that promotes a low level of readthrough of the frameshift mutation by decoding a 4-base codon (Mendenhall et al. 1987). Strains carrying both his $4-38$ and $S U F 1-1$ have a $\mathrm{His}^{+}$phenotype at $30^{\circ} \mathrm{C}$, but at $37^{\circ} \mathrm{C}$ the cells remain $\mathrm{His}^{-}$. This provides the 
Table 1. Yeast strains

\begin{tabular}{|c|c|}
\hline Strain & Genotype \\
\hline PLY36 & MAT $\alpha$ upf1-2 his4-38 SUF1-1 met14 \\
\hline PLY36A & MAT $\alpha$ upf1-2 his4-38 suf $1^{+}$met14 \\
\hline PLY102 & 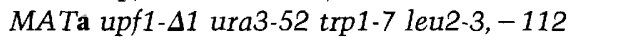 \\
\hline PLY149 & PLY102 [YRpPL14] \\
\hline PLY150 & PLY102 [YRpPL15] \\
\hline PLY171 & PLY102 [YRpPL81] \\
\hline PLY153 & MAT $\alpha$ upf1- $\Delta 1$ ura3-52 trp1- $\Delta 1$ rpb1-1 \\
\hline PLY154 & $\begin{array}{l}\text { MAT } \alpha \text { upf1- } \Delta 1 \text { ura3-52 trp1- } \Delta 1 \text { rpb1-1 his4-38 } \\
\text { leu2-1 }\end{array}$ \\
\hline PLY155 & $\begin{array}{l}\text { MAT } \alpha \text { upf1- } \Delta 1 \text { ura3-52 trp1- } \Delta 1 \text { rpb1-1 his } 4-38 \\
\text { SUF1-1 leu2-1 }\end{array}$ \\
\hline PLY167 & $\begin{array}{l}\text { MATa upf1- } \Delta 2 \text { ura3-52 trp1- } \Delta 1 \text { rpb1-1 his4-713 } \\
\text { leu2-3, }-112 \text { lys2-20 }\end{array}$ \\
\hline PLY172 & $\begin{array}{l}\text { MATa upf1- } \Delta 1 \text { ura3-52 trp1-7 rpb1-1 } \\
\text { leu2-3,-112 [YRpPL14] }\end{array}$ \\
\hline PLY173 & $\begin{array}{l}\text { MATa upf1- } \Delta 1 \text { ura3-52 trp1-7 rpb1-1 } \\
\text { leu2-3, -112 [YRpPL15] }\end{array}$ \\
\hline PLY176 & $\begin{array}{l}\text { MATa upf1- }-1 \text { ura3-52 trp1-7 rpb1-1 } \\
\text { leu2-3,-112 [YRpPL81] }\end{array}$ \\
\hline PLY177 & 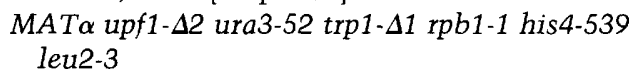 \\
\hline
\end{tabular}

Names in brackets refer to plasmids carrying HIS4-lacZ fusion genes that have been integrated into the chromosome at the trp1 locus.

basis for selection of upf (up frameshift) mutations, which confer a modest increase in gene expression sufficient to render the cells $\mathrm{His}^{+}$at $37^{\circ} \mathrm{C} / \mathrm{Culbertson}$ et al. 1980).

Our results indicate that recessive loss of function of a protein product encoded by UPF1, one of the genes identified in the selection described above, confers a $\mathrm{His}^{+}$ phenotype at $37^{\circ} \mathrm{C}$ in his4-38 SUF1-1 strains through restabilization of his4-38 mRNA. We show that enhanced mRNA stability is not a function of changes in translational readthrough of the frameshift mutation or the downstream stop codon that it generates. On the basis of these and other experiments, we propose that the wildtype $U P F 1^{+}$gene product performs an important function in a previously unknown pathway leading to destabilization of transcripts containing a premature translational termination codon.

\section{Results}

Mutations conferring a $\mathrm{Upf}^{-}$phenotype /Culbertson et al. 1980) potentially could affect translational fidelity or mRNA metabolic processes such as transcription, processing, or stability. Our approach in identifying those mutations that specifically affected mRNA stability was, first, to screen the mutants for elevated accumulation of his4-38 mRNA. This led to the identification, cloning, and molecular analysis of the UPF1 gene, which is not essential for vegetative growth (Leeds 1991).

Mutations in UPFl cause increased accumulation of his4-38 $m R N A$

The haploid strains used in this study (Table 1) all con- tain either upf1-2 or a deletion of UPF1 designated upf1$\Delta 1$ or upf1- $\Delta 2$ (see Materials and methods). These deletions result in complete loss of UPF1 function and confer the same phenotype as upf1-2 (Leeds 1991). Derivatives of these strains that contain $U P F 1^{+}$on a plasmid are denoted by the strain number followed by a plus sign $(+)$ in parenthesis. Derivatives that contain only a vector are denoted by the strain number followed by a minus sign $(-)$.

The extent of mRNA accumulation was initially estimated by densitometric scanning of autoradiographs from Northern blots. his4-38 mRNA accumulation was normalized to actin mRNA accumulation, which is unaffected by the SUF1 or upf1 mutations. We measured the extent of his4-38 mRNA accumulation in strains PLY36 + | and PLY36 - ) (Table 1). We found a 3.8-fold increase in his4-38 mRNA accumulation in PLY36|-) compared with the $U P F 1^{+}$derivative PLY36|+ ) (Fig. 1A, lanes 1 and 2). Because the presence or absence of a $U P F 1^{+}$gene is the only genetic difference between the two strains, the increase is presumed to be a consequence of the upf1-2 mutation in PLY36(-). We also examined his4-38 mRNA accumulation in a similar set of strains [PLY36A|+| and PLY36A $\mid-1]$ that lacked SUF1-1 (Table 1). We found a 3.2-fold increase in his4-38 mRNA accumulation in PLY36A (-) compared with the $U P F 1^{+}$derivative PLY36A $|+|$(Fig. 1A, lanes 3,4). This increase is also a consequence of the upf1-2 mutation.

We found that SUF1-1 causes a 1.4-fold increase in the relative accumulation of his 4-38 mRNA (Fig. 1A, cf. lanes 1,3|. Thus, upf1-2 has a much more pronounced effect on accumulation than does the tRNA suppressor, and upf1-2 appears to affect mRNA accumulation in a manner independent of SUF1-1. For this reason, the effects of the tRNA suppressor on mRNA accumulation were not studied further. All subsequent experiments reported below were performed with $\operatorname{suf1}{ }^{+}$strains that also carry either upf1- $\Delta 1$ or upf1- $\Delta 2$.

Loss of UPFl function stabilizes his4-38 mRNA, whereas $\mathrm{HIS}^{+}{ }^{+} \mathrm{mRNA}$ is unaffected

The increased accumulation of his4-38 mRNA in $\mathrm{Upf}^{-}$ strains could be the result of changes in either the rate of synthesis or decay of the mRNA. To measure decay

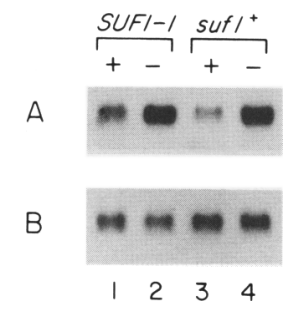

Figure 1. Northern blot analysis of his 4-38 strains. Total RNA $(10 \mu \mathrm{g} /$ lane) is from strains PLY36|+) (lane 1), PLY36| - ) (lane 2), PLY36A (+) (lane 3), and PLY36A|- ) (lane 4). Filters were hybridized with probes derived from HIS $4(A)$ and $A C T 1(B)$. 
rates, strains were constructed that carry $r p b 1-1$, a mutation in a gene coding for a subunit of RNA polymerase II that causes temperature-sensitive growth (Nonet et al. 1987). Shifting strains to the restrictive temperature $\left(36^{\circ} \mathrm{C}\right)$ results in rapid cessation of polymerase II transcription, allowing for direct measurement of the decay rates of specific mRNAs with a quantitative Northern blotting procedure on the basis of direct radioisotope counting (Herrick et al. 1990; see Materials and methods).

The accumulation and rate of decay was determined for $\mathrm{HIS4}^{+}$and his4-38 mRNA isolated from strains that carry the chromosomal deletion upf1- $\Delta 1$. Two of the strains carry the HIS4 ${ }^{+}$allele $[$PLY $153|+|$ and PLY153(-\|], and two carry his4-38 [PLY154|+) and PLY154(-)] (Table 1).

$\mathrm{HIS}^{+}{ }^{+}$mRNA accumulation is not affected by loss of UPF1 function (Fig. 2A; Table 2). Also, the half-life of HIS4 $^{+}$mRNA in PLY153(+) is nearly identical to its half-life in PLY153(-) (18 vs. $17 \mathrm{~min}$, respectively). In $U P F 1^{+}$strains the accumulation of his4-38 mRNA is reduced three- to fourfold compared with $H I S 4^{+}$mRNA. The half-life is reduced from 17-18 $\mathrm{min}$ to $4 \mathrm{~min}$ (Fig. 2B; Table 2). Deletion of the UPF1 gene causes a three- to fourfold increase in his4-38 mRNA accumulation, which is accompanied by an increase in mRNA half-life from 3-4 $\min$ to $14 \mathrm{~min}$ (Fig. 2B; Table 2).

These results suggest that the accelerated mRNA de- cay rate resulting from the presence of the his4-38 frameshift mutation depends on UPF1 function. When UPF1 is deleted, the decay rate, although still slightly reduced, is similar to the wild-type HIS4 decay rate. Also, the net changes in mRNA accumulation can be explained by changes in mRNA half-life without assuming any changes in transcription rates. If deletion of UPF1 caused any such change, we should have seen an increase in the accumulation of $\mathrm{HIS}^{+}{ }^{+}$mRNA when UPF1 was deleted, but no increase was observed.

Loss of UPF1 function stabilizes a limited class of mRNAs

We examined mRNAs encoded by wild-type, nonsense, and frameshift alleles for a number of different genes to determine whether accumulation and stability were affected by loss of UPF1 function (Table 2; Fig. 2). Wildtype transcripts were tested that vary in half-life over a wide range, including $A C T 1$ and $P G K 1$ mRNAs $130-60$ min) as well as STE3 and MAT $\alpha 1$ mRNAs (4 min). With the exception of the URA3 transcript, which is discussed below, none of the wild-type mRNAs tested showed differences in accumulation or turnover in $U P F 1^{+}$compared with upf1- $\Delta 1$ strains (Table 2 ; Fig. 2A).

In strains carrying a functional $U P F 1^{+}$gene, mRNAs transcribed from two nonsense alleles (his4-539, leu2-1)
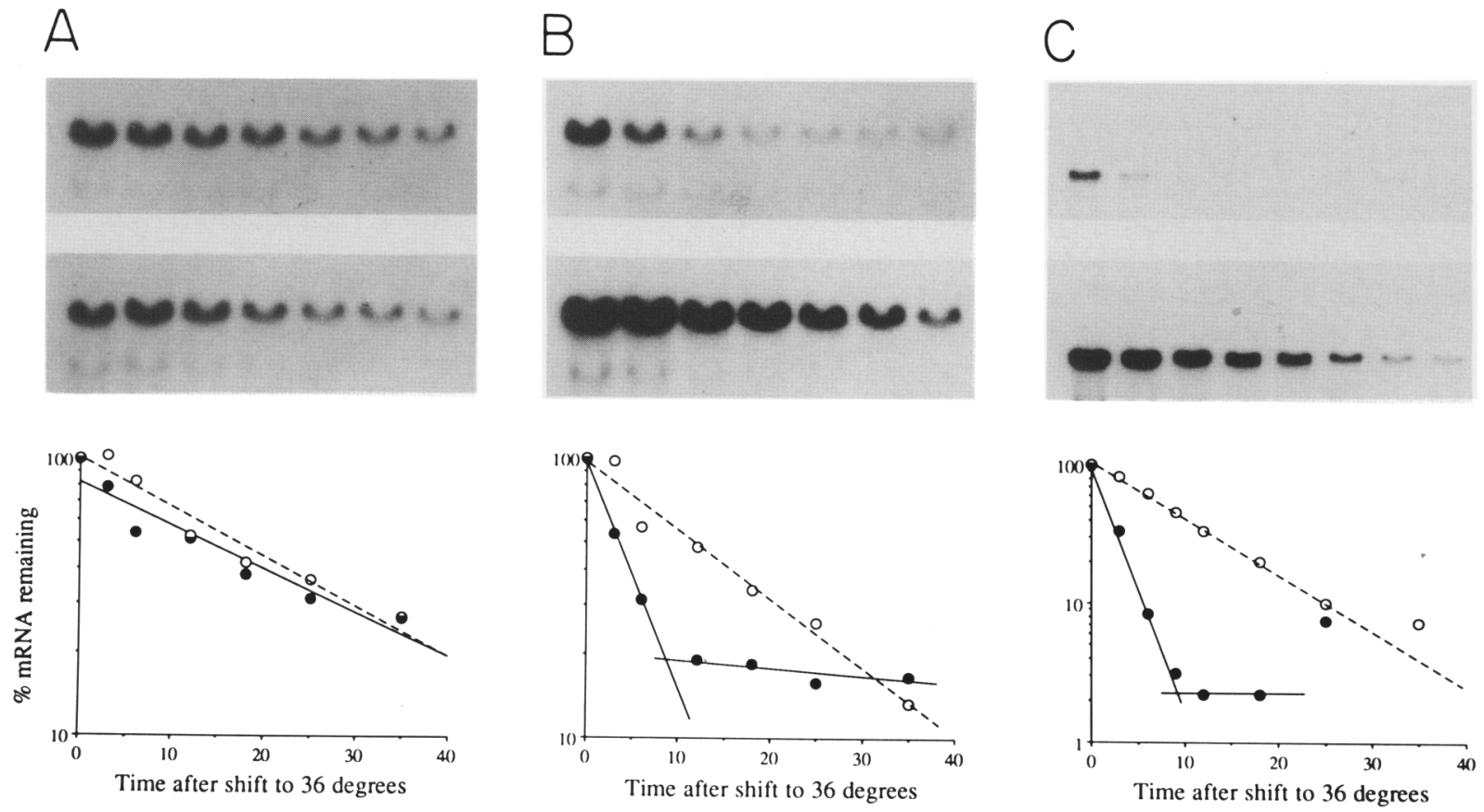

Figure 2. Decay rates of his4 transcripts. The upper autoradiographs are derived from $U P F 1^{+}$strains; the lower autoradiograms are from upf1- $\Delta 1$ or upf1- $\Delta 2$ strains. (A) Decay rate of the $H I S 4^{+}$transcript measured in strains PLY153|+) and PLY153(-); $(B)$ decay rate of the his4-38 transcript measured in strains PLY154|+) and PLY154(-); (C) decay rate of the his4-539 transcript measured in strains PLY177 $|+|$ and PLY177 $|-| \cdot(A, B)$ Time points were taken $0,3,6,12,18,25$, and 35 min after the cultures were shifted to $36^{\circ} \mathrm{C}$; $|C|$ there is an additional 9-min time point. Solid circles and lines refer to $U P F 1^{+}$; open circles and dashed lines refer to upf1- $\Delta 1$. 
Table 2. Half-lives and accumulations of endogenous mRNAs

\begin{tabular}{|c|c|c|c|c|}
\hline \multirow[b]{2}{*}{ Strain } & \multirow[b]{2}{*}{ Transcript $^{\mathbf{a}}$} & \multirow{2}{*}{$\begin{array}{l}\text { Relative abundance } \\
{\left[\left(\text { upf } 1^{-} / U P F 1^{+}\right)_{t=0}\right]}\end{array}$} & \multicolumn{2}{|c|}{ Half-life (min) } \\
\hline & & & $U P F 1^{+}$ & upf1- \\
\hline \multicolumn{5}{|l|}{ I } \\
\hline PLY154 & his4-38 & 4.3 & 4 & 14 \\
\hline PLY177 & his4-539 & 4.8 & 2 & 8 \\
\hline PLY154 & leu2-1 & 3.4 & 4 & 16 \\
\hline PLY177 & leu2-3 & 4.4 & 3 & 7 \\
\hline \multicolumn{5}{|l|}{ II } \\
\hline PLY153 & HIS4 & 0.9 & 18 & 17 \\
\hline PLY167 & his4-713 & 0.8 & 14 & 15 \\
\hline PLY153 & LEU2 & 1.0 & 14 & 14 \\
\hline PLY153 & $M A T \alpha 1$ & 1.2 & 4 & 4 \\
\hline PLY153 & STE3 & 0.8 & 4 & 4 \\
\hline PLY153 & $A C T 1$ & 1.1 & 37 & 34 \\
\hline PLY153 & $P G K 1$ & 0.9 & 60 & 60 \\
\hline PLY153 & $P A B 1$ & 1.2 & 13 & 11 \\
\hline
\end{tabular}

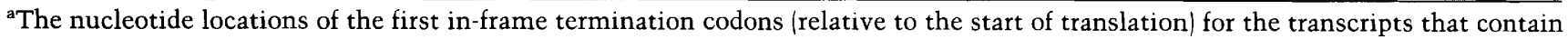
premature stop codons are his4-38, 178; leu2-3, 256; and his4-713, 2275. The his4-539 mutation has been mapped upstream of the his 4-17 mutation, which is located at nucleotide position 688 (Fink and Styles 1974; Donahue et al. 1982). The location of the stop codon in leu2-1 is not known. The HIS4 ${ }^{+}$-coding region is 2397 bp (Donahue et al. 1982); the LEU2 ${ }^{+}$-coding region is 1092 bp (Andreadis et al. 1984). All strains contain suf ${ }^{+}$.

and two frameshift alleles (his4-38, leu2-3) all exhibit at least a three- to fourfold decrease in accumulation and mRNA half-life compared with the $\mathrm{HIS4}^{+}$or $\mathrm{LEU2}^{+}$ transcripts (Table 2). In upf1- $\Delta 1$ or upf1- $\Delta 2$ strains the accumulation and half-life of the nonsense and frameshift mRNAs always increases but never exceeds that of the corresponding wild-type mRNA (Table 2; Fig. 2).

However, not all frameshift mutations affect the stability of mRNA. In strains containing a $U P F 1^{+}$gene we found that the extent of accumulation and rate of turnover of mRNA encoded by the frameshift allele his4-713 (14-min half-life) was similar to HIS4 ${ }^{+}$mRNA (17-min half-life; Table 2). Furthermore, his4-713 mRNA accumulation and turnover was unaffected by loss of UPF1 function. This exceptional behavior may be the result of the location of the frameshift mutation in his4-713. The single nucleotide insertion results in premature translational termination near the $3^{\prime}$ end of HIS4 mRNA 120 nucleotides upstream of the normal termination codon (Donahue et al. 1981). The his4-38, his4-539, and leu2-3 mutations are all known to map in the $5^{\prime}$ third of their respective mRNAs, whereas the position of leu2-1 has not been established (Fink and Styles 1974; Donahue et al. 1981, 1982; I. Edelman and M. Culbertson, unpubl.). Similar position-dependent effects on mRNA stability have been reported for nonsense mutations in the URA3 gene (Losson and Lacroute 1979).

$U R A 3^{+}$mRNA shows a 1.9 -fold $( \pm 0.1)$ increase in accumulation in strain PLY153(-) compared with PLY153|+) (Tables 1 and 2; Fig. 3). When decay rates were determined (Fig. 3 ) it was found that URA3 mRNA had a 2-min half-life in PLY153(-) compared with a 3 -min half-life in PLY153 $1+1$. Thus, the increased accumulation of URA3 mRNA resulting from loss of UPF1 function is not the result of a corresponding increase in URA3 mRNA half-life. An increase in the rate of transcription is the most likely explanation for the increase in accumulation. Detailed studies presented elsewhere support this conclusion (see Discussion).

\section{Changes in mRNA stability due to loss of UPF1 function are unrelated to the extent of productive translational readthrough}

To monitor productive translation downstream of a stop codon, integrative plasmids were constructed in which $l a c Z$ was fused downstream of a fragment containing the HIS4 promoter and part of the HIS4 $4^{+}$or his $4-38$ reading frame (Fig. 4A and 4B; see Materials and methods). A third fusion, designated his4-38, $-U A A:$ lacZ, contains multiple UAA stop codons in all three reading frames inserted just upstream of the his4-38 frameshift mutation (Fig. 4C). Haploid strains PLY149, PLY150, and PLY171 carry a single, chromosomally integrated copy of the $\mathrm{HIS4}^{+}:$lacZ, his4-38:lacZ, and his4-38,-UAA: lac $Z$ fusions, respectively.

Strains containing the $\mathrm{HIS4}^{+}$: lacZ fusion exhibit relatively high levels of $\beta$-galactosidase activity, producing a dark-blue color in in situ X-gal assays after $15 \mathrm{~min}$ (Fig. 4A). Quantitative assays of several transformants confirmed that there is no increase in $\beta$-galactosidase activity in upf1- $\Delta 1$ strains relative to UPF1 ${ }^{+}$strains [activity (upf1- $\left.\triangle 1 / U P F 1^{+}\right)=0.94 \pm 0.04$ ). Antibodies directed against $\beta$-galactosidase detect a single $140-\mathrm{kD}$ band on Western blots, which is similar to the predicted molecular mass of $136 \mathrm{kD}$ for the fusion protein (Fig. 4D, lanes 2,3 ). This band is absent from strain PLY102, which does not contain a lacZ fusion plasmid (Fig. 4D, lane 1). 
A

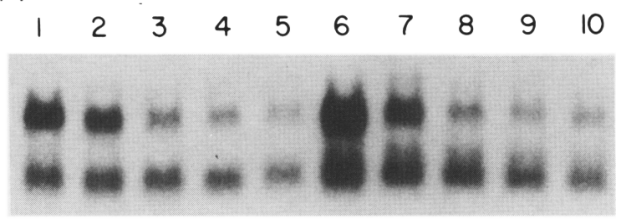

$\mathrm{B}$

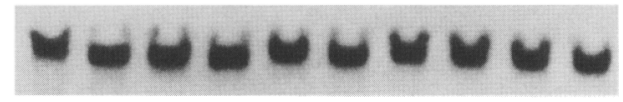

C

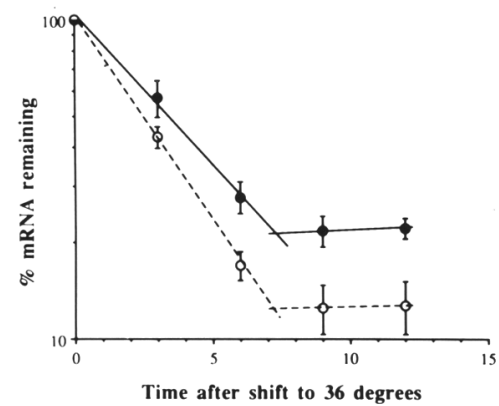

Figure 3. Decay rate of $U R A 3 \mathrm{mRNA}$. Decay rates are shown for strains PLY153 $|+|($ lanes 1-5) and PLY153|- ) (1anes 6-10). Time points were taken $0,3,6,9$, and 12 min after cultures were shifted to $36^{\circ} \mathrm{C}$. (A) $U R A 3^{+}$mRNA decay. Hybridization to a $U R A 3$ probe produces two bands in each of these strains. The strains carry both the ura3-52 mutation and a wild-type copy of URA3 inserted into UPF1 to construct upf1- $\Delta 1$ (see Materials and methods). The upper band comigrates with the $1-\mathrm{kb}$ wildtype URA3 transcript; the lower band comigrates with an mRNA seen in ura3-52 strains. Both mRNAs appear to be under the control of the $U R A 3$ transcription promoter, because growth in the presence of 6-azauracil induces both transcripts (Losson and Lacroute 1981; data not shown). $(B)$ The filter shown in $A$ rehybridized with an $A C T 1$ probe. $(C)$ Decay rate of the 1-kb wild-type URA3 transcript (upper band in $A$ ). Data points and error bars were derived from three independent hybridization experiments. Solid circles and lines refer to $U P F 1^{+}$; open circles and dashed lines refer to upf1- $\Delta 1$.

Decay-rate experiments with strains that contain $1 a c Z$ fusions are shown in Figure 5. The fusion alleles each produce a $3.6-\mathrm{kb}$ and an $8.4-\mathrm{kb}$ transcript that hybridize to a lacZ probe (see legend to Fig. 5). Both transcripts show the same pattern of response to changes in UPF1 expression. The transcripts associated with the $H I S 4^{+}$: lacZ fusion are not stabilized in a upf1- $\Delta 1$ background (Fig. 5A; Table 3). On the basis of the $\beta$-galactosidase assays, Western blots, and mRNA accumulation and half-life measurement, we conclude that there is no significant difference in expression of the $\mathrm{HIS4}^{+}: \mathrm{lacZ}$ fusion protein in $U P F 1^{+}$and upf1- 11 strains.

Strains carrying the his 4-38:1acZ fusion produce much less $\beta$-galactosidase activity than the $\mathrm{HIS4}^{+}$: lacZ fusion does, although some blue color was detected in both the UPF1 ${ }^{+}$and upf1- $\Delta 1$ strains after $16 \mathrm{hr}$ of devel-

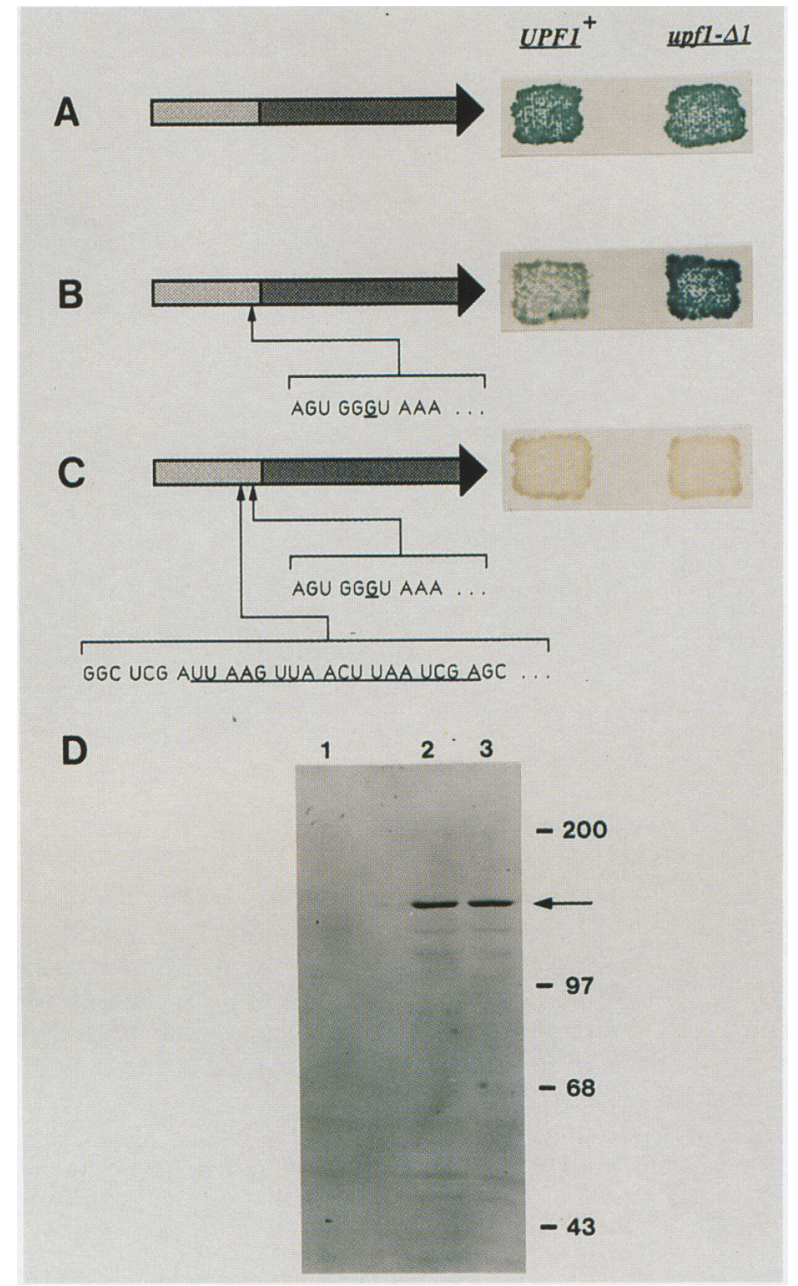

Figure 4. $\beta$-Galactosidase activity in lacZ fusion strains. The light portions of the arrows left of each panel denote HIS4 sequences; the dark portions represent lacZ. Transcription is in the direction indicated. UPF $1^{+}$and upf1- $\Delta 1$ derivatives of strains containing the lac $Z$ fusion alleles were constructed as described in Materials and methods. Underlined sequences represent insertions defining the his $4^{-}$mutations. (A) $\mathrm{HIS4}^{+}$: lacZ [strains PLY149(土)]. A 1.5-kb fragment containing $1 \mathrm{~kb}$ of the $5^{\prime}$-untranslated region of $\mathrm{HIS4}^{+}$and the first $0.5 \mathrm{~kb}$ of the $\mathrm{HIS}_{4}{ }^{+}$open reading frame was fused in-frame to lacZ in the plasmid PMC1790. The $\beta$-galactosidase filter assay shown at right was allowed to develop for $15 \mathrm{~min}$. $(B)$ his4-38: lacZ [strains PLY150( \pm )]. Construction details are identical to $A$ except that the fragment introduced into PMC1790 contains the his4-38 mutation. The $\beta$-galactosidase filter assay was allowed to develop for $16 \mathrm{hr}$. (C) his4-38,-UAA:lacZ [strains PLY171( \pm$)$. Construction details are the same as $A$ except that the his 4 fragment contains both the his4-38 mutation and an oligonucleotide insertion at a unique $\mathrm{XhoI}$ site 80 nucleotides upstream of the his 4-38 mutation. The $\beta$-galactosidase filter assay was allowed to develop for $16 \mathrm{hr}$. $(D)$ Western blot analysis of $\mathrm{HIS4}^{+}$: lacZ strains with antibodies directed against $\beta$-galactosidase. Equal amounts of total protein from strains PLY102 (lane 1); PLY149| + ) (lane 2); and PLY149| - ) (lane 3) were loaded on each lane. The arrow indicates the single band that is present in lanes 2 and 3 but absent in lane 1 . 

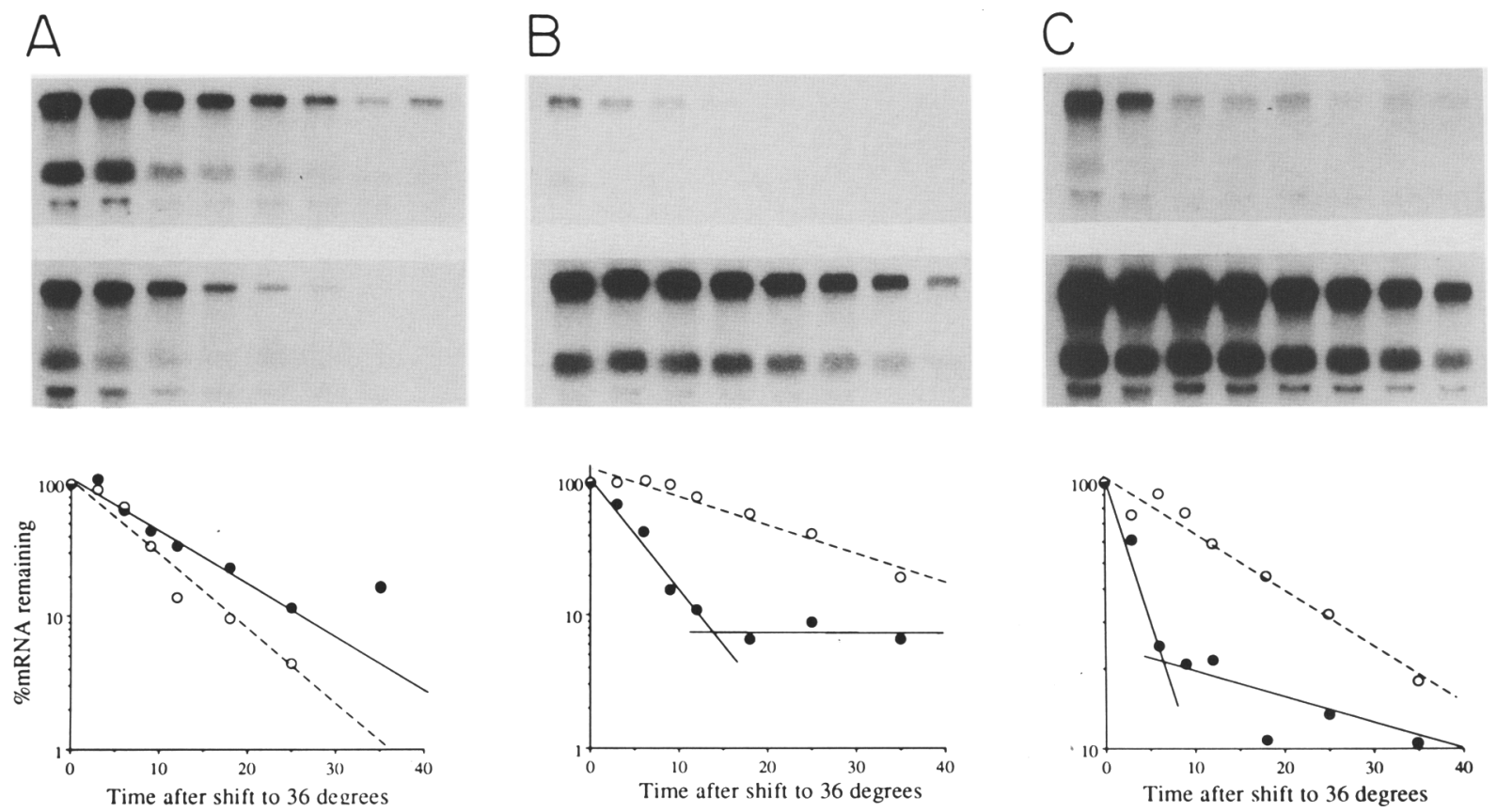

Figure 5. Decay rates of the lacZ gene fusion transcripts. Half-lives were measured in strains PLY172( \pm$)\left(H I S 4^{+}: 1 a c Z\right)(A)$; PLY173( \pm ) (his4-38:lacZ) (B); and PLY176) \pm ) (his4-38, -UAA:lacZ) (C). The upper autoradiograph in each section is derived from the $U P F 1^{+}$variant of these strains; the lower autoradiograph is derived from the upf1- $\Delta 1$ variant. A lacZ probe detects two major RNA species of $\sim 8.4 \mathrm{~kb}$ (upper band) and $\sim 3.6 \mathrm{~kb}$ (lower band) in each strain. Hybridization to a single-stranded probe has shown that both of these RNAs are transcribed in the direction expected if initiation were occurring at the HIS4 promoter. The size of the 3.6-kb band is consistent with transcription initiating at the normal HIS4 site and terminating close to the $3^{\prime}$ end of the lacZ sequences. The 8.4-kb band hybridizes to TRP1 sequences, which are located downstream of the lac $Z$ fusion alleles. The larger mRNA is probably produced by transcription initiating at the HIS 4 site and proceeding through $l a c Z$, pMC1790 bacterial sequences, and TRP1 with transcription terminating at the normal TRP1 termination site. Half-lives were measured for both the 3.6- and 8.4-kb transcripts (see Table 3), but only data from the larger transcript are plotted below. Time points were taken $0,3,6,9,12,18,25$, and 35 min after the cultures were shifted to $36^{\circ} \mathrm{C}$. Solid circles and lines refer to $U P F 1^{+}$; open circles and dashed lines refer to upf1- $\Delta 1$.

opment (Fig. 4B). The activity was too low to obtain quantitative data, but qualitatively, the results of the in situ filter assay suggest that $\beta$-galactosidase activity is higher in the upf1- $\Delta 1$ strain than in the UPF1+ ${ }^{+}$strain. The his4-38 mutation exhibits a low level of leakiness that is enhanced phenotypically in strains lacking UPF1 function.

Both the steady-state level and the half-life of his4-
38 : lac $Z$ mRNA increase approximately fourfold in upf1- $\Delta 1$ strains (Fig. $5 B$; Table 3). The half-life of the his4-38 : lacZ transcript was also measured in strains derived from PLY150, which does not contain rpb1-1, by inhibiting transcription with thiolutin (Herrick et al. 1990). Results were consistent with those obtained by inhibiting transcription at the restrictive temperature in strains carrying $r p b 1-1$.

Table 3. Half-lives and accumulations of lacZ fusion $m R N A s$

\begin{tabular}{|c|c|c|c|c|}
\hline \multirow[b]{2}{*}{ Strain } & \multirow[b]{2}{*}{ Transcript } & \multirow{2}{*}{$\begin{array}{l}\text { Relative abundance } \\
{\left[\left\{\text { upf } 1-\Delta 1 /\left.U P F 1^{+}\right|_{t=0}\right]\right.}\end{array}$} & \multicolumn{2}{|c|}{ Half-life $(\min )$} \\
\hline & & & $U P F 1^{+}$ & $u p f 1-\Delta 1$ \\
\hline \multirow[t]{2}{*}{ PLY172 } & $\mathrm{HIS}^{+}: \mathrm{lacZ}$ & 0.7 & 8 & 5 \\
\hline & & 0.7 & 6 & 5 \\
\hline \multirow[t]{2}{*}{ PLY173 } & his4-38 : lacZ & 4.4 & 4 & 14 \\
\hline & & 4.1 & $<3$ & 13 \\
\hline \multirow[t]{2}{*}{ PLY176 } & his4-38,-UAA : lacZ & 4.9 & 3 & 14 \\
\hline & & 7.0 & $<3$ & 21 \\
\hline \multirow[t]{2}{*}{ PLY150 } & his4-38: lacZ & 5.0 & 4 & 20 \\
\hline & & ND & 3 & 17 \\
\hline
\end{tabular}

Values on the first line of each entry are derived from measurements of the 8.4-kb (upper) band seen on the autoradiograms in Fig. 4. Data on the second line of each entry are from the 3.6-kb (lower) band. Strain PLY150 does not carry the rpb1-1 mutation. Half-lives were measured by inhibiting transcription with thiolutin (see Materials and methods). (ND) Not done. 
Increased leakiness in the upf1- strain detected by assaying $\beta$-galactosidase could be the result of enhanced translational readthrough or direct stabilization of his438 mRNA leading to an increased steady-state mRNA concentration. We distinguished between these possibilities by examining the his4-38,-UAA : lacZ fusion. Strains carrying this fusion produce undetectable levels of $\beta$-galactosidase regardless of the presence or absence of a functional UPF1 gene (Fig. $4 \mathrm{C}$ ). These results indicate that the leaky phenotype of his4-38:1acZ fusion is abolished completely when UAA stop codons are introduced upstream of the his4-38 mutation. There is no detectable translational readthrough of this fusion mRNA.

The his4-38, -UAA : lacZ transcript accumulates in a upf1- $\Delta 1$ strain to the same extent as the his4-38:lacZ transcript (Fig. 5C). Half-life measurements confirm that the observed fourfold increase in steady-state accumulation of mRNA is associated with a similar increase in mRNA stability (Fig. 5C; Table 3). The combined results suggest that mRNA stabilization resulting from loss of UPF1 function is unrelated to and independent of the level of readthrough of frameshift mutations or stop codons in the mRNA.

Changes in mRNA stability due to loss of UPF 1 function are not the result of ribosome bypass of a stop codon

The $\beta$-galactosidase assays described above measure the extent of translationally productive readthrough of a termination codon but do not, by themselves, constitute a measure of how effectively ribosomes can bypass a stop codon and remain bound to the mRNA. We tested the extent to which ribosomes might bypass a stop codon, migrate downstream, and confer stabilization through a passive protection mechanism. To determine whether this was occurring, we examined the distribution of the his4-38,-UAA: lacZ transcript on polyribosomes in both UPF1 ${ }^{+}$and upf1- $\Delta 1$ derivatives of strain PLY176. Polyribosomes from both strains were fractionated by centrifugation through sucrose gradients, and the distribution of ribosomes on the fusion mRNA was determined by Northern hybridization analysis of RNA extracted from each fraction (Fig. 6). As a control, filters were also hybridized to an $A C T 1$ probe /which detects actin mRNA). The results indicate that loss of UPF1 function does not substantially change the extent of ribosome loading on the stabilized fusion mRNA. Given the magnitude of the change in mRNA half-life, the potential change in ribosome loading should have been detected if it were occurring. Therefore, we conclude that the changes in mRNA stability resulting from loss of UPF1 function are not the result of an enhanced rate of ribosome bypass beyond a translation termination codon.

\section{Discussion}

The mechanism responsible for destabilization of tran- scripts containing premature termination signals is not understood. Formally, premature stop codons are cis-acting elements that promote accelerated mRNA decay rates. In this study we present data supporting the conclusion that the UPF1 gene product is a trans-acting component of a degradative pathway that acts specifically on the class of mRNAs containing premature stop codons.

Originally, upf $1^{-}$mutations were isolated by selecting for enhanced suppression of the his4-38 frameshift mutation in the presence of a tRNA frameshift suppressor, SUF1-1. By using a clone of UPF1, strains were constructed that lack the tRNA suppressor and contain a null UPF1 allele constructed in vitro and introduced into yeast by gene replacement. We have shown that the his 4 38 transcript is stabilized in these strains. The increase in mRNA half-life causes a corresponding increase in steady-state mRNA level. We have also observed a stabilizing effect on the mRNA produced by a his438 : lacZ fusion; the nonsense alleles, his4-539 and leu21 ; and the frameshift mutation, leu2-3. With the exception of leu2-1, all of the mutations generate translationtermination codons in-frame toward the $5^{\prime}$ end of the respective coding regions. The position of the premature stop codon in leu2-1 is unknown.

In contrast, the his4-713 frameshift mutation, which generates a termination codon in-frame near the $3^{\prime}$ end of the coding region, produces a relatively stable transcript in $U P F 1^{+}$strains compared with wild-type HIS4 mRNA. Furthermore, the half-life of his4-713 mRNA is not altered by loss of UPF1 function. Additional wildtype mRNAs that have a broad range of inherent decay rates were also examined, and the turnover rates of these mRNAs were unaltered in strains lacking $U P F 1^{+}$function.

Taken together, these results suggest that the UPF1 product promotes the specific degradation of mRNAs in which translation is interrupted prematurely. The interdependence of translation and mRNA stability in this system suggests that the UPF1 product could have a primary mode of action in mRNA degradation or in translation. In the latter case, the changes in mRNA half-life could represent a secondary consequence of loss of a translational component.

Data from gene fusions between the his 4 promoter/ coding region and $l a c Z$ show that even in the absence of a tRNA suppressor, there is a low level of translational readthrough of the his4-38 mRNA. Therefore, it seemed possible that the UPF1 mutations might act by enhancing this low-level readthrough, allowing ribosomes that bypass the stop codon to restabilize the mRNA. A mechanism of this type can be used to explain the results of studies of ura3 mutants, where a tRNA nonsense suppressor was shown to stabilize an mRNA that is otherwise destabilized by a premature stop codon (Losson and Lacroute 1979).

Our results show that this mechanism does not explain the stabilizing effect of UPF1 mutations. In a gene fusion where readthrough is abolished completely by the presence of multiple stop codons introduced in the HIS4 
A

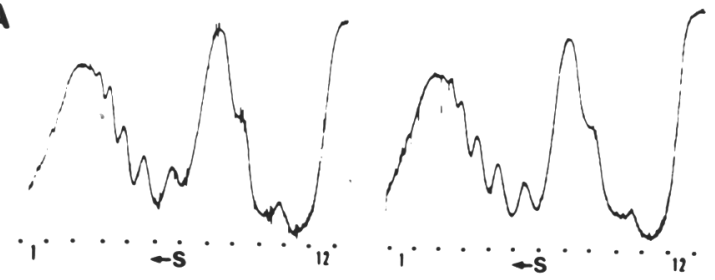

B

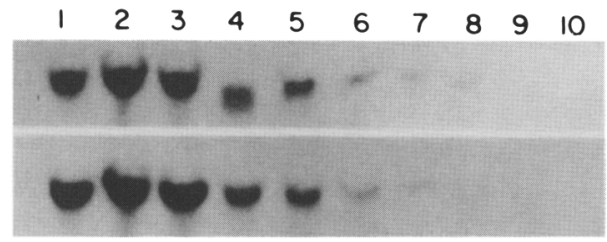

C

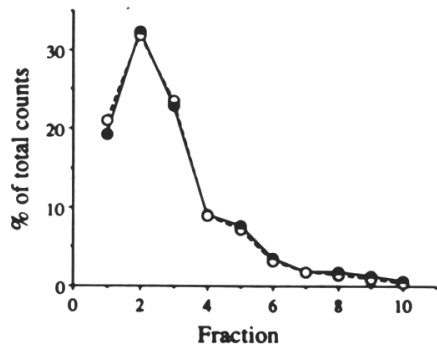

D

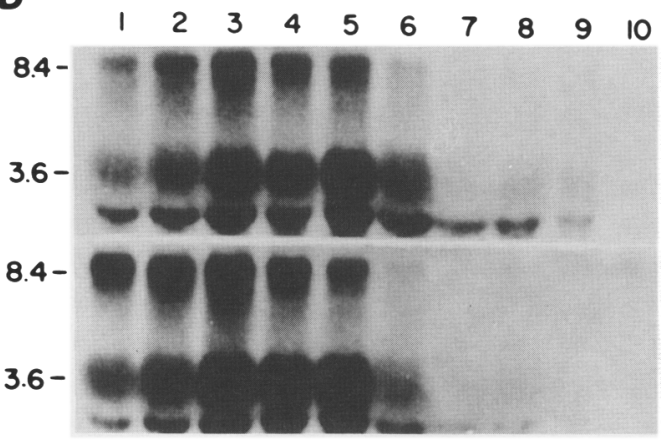

E

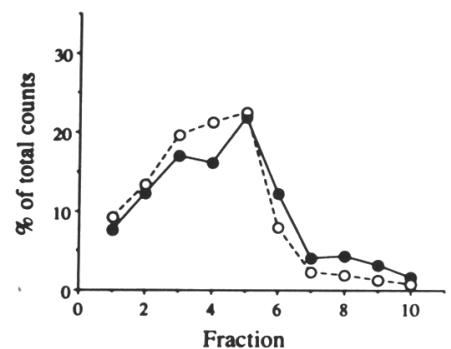

F

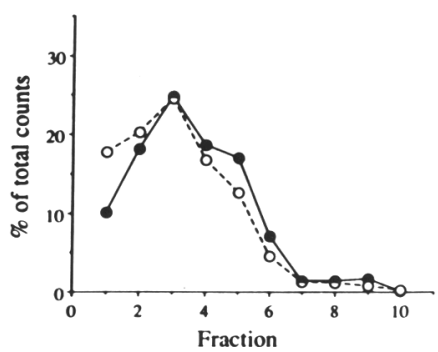

Figure 6. Distribution of his4-38, - UAA : lacZ mRNA on polyribosomes in strains PLY176(+) and PLY176(-1. Extracts containing polyribosomes were fractionated on $12-\mathrm{ml} 15-50 \%$ continuous sucrose gradients. Fractions of $1 \mathrm{ml}$ were collected from the bottom of the gradient and used for Northern analysis. Only the first 10 fractions are shown in the autoradiographs; no hybridizing material was detectable in fractions 11 and 12. Graphs were plotted by counting the activity in each band and normalizing to total counts in fractions 1-10 for that particular band. Solid circles and lines refer to $U P F 1^{+}$; open circles and dashed lines refer to upf1- $\triangle 1$. $(A)$ The absorption profile of gradients containing polyribosomes isolated from PLY176|+) (left) and PLY176|-| (right) monitored at $260 \mathrm{~nm}$. $(B)$ Hybridization with an ACT1 probe. The upper autoradiograph is derived from PLY176|+1; the lower is derived from PLY176|-1. $(C)$ Distribution of counts hybridized to the bands shown in $B .(D)$ Hybridization with a lacZ probe. The upper autoradiograph is derived from PLY176 $1+1$ and has been exposed five times longer than the lower autoradiograph, which is derived from PLY176 -1 . Band sizes are given in kilobases. $(E)$ Distribution of counts hybridized to the $3.6-\mathrm{kb}$ band. $(F)$ Distribution of counts hybridized to the 8.4-kb band. The above experiments were repeated with RNA derived from strain PLY172 to determine the distribution of ribosomes on $\mathrm{HIS}^{+}$: lacZ mRNA. In this case, the peak activity hybridizing to the 8.4- and 3.6-kb bands was found in fraction 2 (data not shown).

region, the corresponding mRNA is stabilized still by loss of UPF1 function. In addition, the tRNA suppressor SUF1-1, whose primary mode of action is to promote readthrough of frameshift mutations, does not, by itself, fully stabilize the his4-38 transcript. The apparent disagreement between our study and that involving the stabilization of ura3 nonsense alleles by nonsense suppressors is probably due to the fact that the tRNA amber nonsense suppressors used in the study of ura3 were more efficient in promoting translational readthrough than is SUF1-1.

Thus, stabilization of his4-38 mRNA in strains lack- ing UPF1 function is not an indirect consequence of increased levels of mistranslation. We also tested the possibility that loss of UPF1 function results in bypass of premature stop codons in a manner that is translationally nonproductive but still affords the mRNA protection from degradation. A bypass mechanism of this type does not occur to an extent that can be detected as a major change in the distribution of ribosomes on the his4-38,-UAA : lacZ fusion transcript in strains deleted for UPF1.

Our studies with various fusions between his4 and $1 a c Z$ also suggest a rationale for how loss of UPF1 func- 
tion causes a phenotype that resembles translational suppression. Although loss of UPF1 function does not confer a $\mathrm{His}^{+}$phenotype in strains containing his4-38, our studies with gene fusions indicate that it does promote a low level of suppression as measured by $\beta$-galactosidase activity. Previous studies indicate that a minimum of $6 \%$ of wild-type HIS4 product is needed to confer a leaky His ${ }^{+}$phenotype (Gaber and Culbertson 1984), so less than this amount of functional product must be produced by loss of UPF1 function in his4-38 strains. Given that his4-38 is itself slightly leaky, the low level of suppression might be accounted for solely by an increase in steady-state level of the his $4-38$ transcript. Therefore, in the original selection for upf mutations in strains containing the tRNA suppressor $S U F 1-1$, enhancement of suppression (translational allosuppression) by a upf 1 mutation might result from the combined effects of mRNA stabilization and tRNA-mediated translational readthrough.

Our results show that in a upf1- background, the halflives of mRNAs derived from the his 4 and leu2 nonsense and frameshift alleles are never greater than the halflives of the wild-type HIS4 and LEU2 transcripts. Coupled with the finding that the stability of wild-type $\mathrm{mR}$ NAs is generally unaffected by UPF1, these results suggest that the upper limit on stability that can be achieved by combining a UPF1 loss-of-function mutation with a nonsense mutation is equivalent to the half-life of the wild-type mRNA. An exception to this rule was found when mutations that generate premature nonsense codons were introduced into the his 4 region of a his 4 : lacZ fusion. The stabilities of the corresponding transcripts in upf1- $\Delta 1$ strains exceeded that of the $\mathrm{HSS}^{+}$: lacZ fusion transcripts. This unexpectedly low stability of $\mathrm{HIS}^{+}$: $1 \mathrm{acZ}$ mRNA could be explained by postulating the existence of a sequence element in HIS4 or $l a c Z$ that destabilizes the mRNA in a manner independent of UPF1 function. Such an element has been shown to exist in the yeast MAT $\alpha 1$ gene (Parker and Jacobson 1990). Because an element of this type is active only when translated, it might destabilize the $\mathrm{HIS4}^{+}$: lacZ transcript but have no effect on transcripts containing premature stop codons.

Important clues regarding UPF1 function may come from our studies of the endogenous $U R A 3^{+}$transcript, which exhibits excess accumulation in upf1- $1^{-}$strains but shows no change in mRNA stability. This result is unusual in several respects. $U R A 3^{+}$mRNA is the only wild-type transcript analyzed in this study whose accumulation is affected by loss of UPF1 function. Because mRNA stability is unchanged, the effect appears to be mediated by a transcriptional mechanism.

More detailed analyses suggest that the effect on $U R A 3$ is transcriptional and is indirectly mediated by the PPR1 gene product, a transcriptional activator of URA3 (S. Peltz, P. Leeds, J.M. Wood, A. Atkin, M.R. Culbertson, and A. Jacobson, in prep.). PPR1 encodes an inherently unstable mRNA (Losson et al. 1983), which we have shown is stabilized by loss of UPF1 function (S.W. Peltz, P. Leeds, M.R. Culbertson, and A. Jacobson, unpubl.). The higher rate of URA3 transcription may therefore be the result of increased expression of PPR1.

An unusual feature of PPR1 mRNA may explain its inherent instability and the stabilization that results from loss of UPF1 function. The leader region of the transcript contains two contiguous AUG codons, followed by a stop codon, three codons later (Losson et al. 1983). Therefore, it may contain a premature stop codon that normally targets the mRNA for degradation by the UPF1-mediated pathway. According to this reasoning, UPF1 may function in a specialized degradation pathway that controls the stabilities of a select subclass of wildtype mRNAs that contain a naturally occurring premature termination signal. An investigation of the effects of UPF1 on mRNAs of this type is currently in progress.

Because the UPF1 product is required for degradation of a particular class of mRNAs, it is possible that UPF1 is the structural gene for a ribonuclease. Alternatively, UPF1 may code for a positive effector of ribonuclease activity. DNA sequence analysis of the UPF1 gene has revealed a potential zinc-dependent nucleic acid-binding domain as well as a region of sequence similarity to the yeast SEN1 gene (Leeds 1991; D.J. Demarini, M. Winey, D. Ursic, F. Webb, and M.R. Culbertson; P. Leeds, J.M. Wood, B. Lee, and M.R. Culbertson; both in prep.). SEN1 is required for tRNA splicing endonuclease activity but is unlikely to be the structural gene for a catalytic subunit of the endonuclease (D. Ursic and M.R. Culbertson, unpubl.). The presence of a nucleic acid-binding domain suggests that the UPF1 product may function through a direct interaction with RNA, a model that is currently being tested.

\section{Materials and methods}

Strains and genetic techniques

The $S$. cerevisiae strains used in this study are described in Table 1. Strains were constructed using standard yeast genetic techniques (Sherman et al. 1979). Media for growth of yeast was described by Gaber and Culbertson (1982). Yeast transformations were performed by using the method of Ito et al. (1983). Bacterial methods, nomenclature, and media were described by Miller (1972). The Escherichia coli strains used for plasmid preparations were MC1066A (Sandbaken and Culbertson 1988) and JM109 (Yanisch-Perron et al. 1985).

\section{Nucleic acid methods}

Yeast chromosomal DNA was prepared by the method of Sherman et al. (1979). Plasmid DNA was prepared from $E$. coli by the method of Birnboim and Doly (1979) or Holmes and Quigley (1981). DNA was sequenced by the method of Sanger et al. (1977).

RNA used to study steady-state mRNA accumulation was isolated by the method of Lindquist (1981). RNA used to measure decay rates was isolated by hot phenol extraction. Cell pellets suspended in $0.6 \mathrm{ml}$ of buffer A $(50 \mathrm{~mm}$ sodium acetate, $10 \mathrm{~mm}$ EDTA) containing 1\% SDS and 1\% diethylpyrocarbonate were extracted twice with buffer A-saturated phenol. Extractions were done at $65^{\circ} \mathrm{C}$ for $5 \mathrm{~min}$. The aqueous phase was then extracted once with phenol/chloroform and precipitated twice 
with ethanol. The RNA pellet was suspended in water and the concentration was measured by absorbance at $260 \mathrm{~nm}$.

\section{Plasmids}

The vectors YCp50, YCpMS38, YEp13, and pMC1790 are described by Rose et al. (1987), Sandbaken and Culbertson (1988), Broach et al. (1979), and Casadaban et al. (1983), respectively.

A copy of $U P F 1^{+}$can be obtained on either a $4.2-\mathrm{kb}$ EcoRIBamHI fragment or a 4.6-kb ClaI-BamHI fragment (Leeds 1991). (The EMBL/GenBank DNA sequence accession number for UPF1 is M76659.) YCpPL63 was constructed by inserting the $4.2-\mathrm{kb} \mathrm{UPF1}{ }^{+}$fragment into EcoRI/BamHI-digested YCp50, which also contains $U R A 3^{+}$. YCpPL53 was constructed by inserting the $4.6-\mathrm{kb} \mathrm{UPF} 1^{+}$fragment into ClaI/BamHI-digested YCpMS38, which also contains $T R P 1^{+}$. YEpPL55 was constructed by ligating a $B a m H I$ linker on the ClaI end of the $4.6-\mathrm{kb}$ $U P F 1^{+}$fragment and inserting the end-modified fragment into BamHI-digested YEp13, which also contains LEU2 ${ }^{+}$.

Plasmids YIp309 and B134 contain the $5^{\prime}$-untranslated region and the HIS4A-coding region of HIS4 and his4-38, respectively. Digestion of each plasmid with BalI and ClaI releases a $1.5-\mathrm{kb}$ fragment. The Ball site is 1036 bases upstream of the start of translation, whereas the ClaI site in HIS $4 A$ is located 340 bases downstream of the site of the his4-38 mutation. A BamHI linker (CGGATCCG) was ligated into the ClaI site of each plasmid following treatment with Klenow enzyme. The resulting BallBamHI fragment from YIp309 was inserted into Smal/BamHIdigested pMC1790 to construct the $\mathrm{HIS4}^{+}$: lacZ fusion plasmid YRpPL14 (Fig. 4A). The same procedure was used to construct the his4-38/lacZ fusion plasmid YRpPL15, except that the BalI-BamHI fragment was derived from B134 (Fig. 4B). The structures of both plasmids were verified by DNA sequence analysis.

The plasmid YRpPL81, which contains the his4-38, -UAA: lacZ gene fusion, was constructed as follows. YRpPL15, which contains the HIS4A region, including the his4-38 mutation, was digested with $X h O I$ at a unique site 96 nucleotides downstream of the start of translation and 80 nucleotides upstream of the his $4-38$ mutation. The resulting linear fragment was treated with Klenow enzyme to produce blunt ends. The nucleotide linker TTAAGTTAACTTAA (Suppressible Reading Frame Termination Linker; Pharmacia) was added in with the blunt-ended fragment and ligated by $\mathrm{T} 4$ ligase.

The DNA fragment used to make the HIS4 hybridization probe consisted of a 2.4-kb PvuII fragment from plasmid B137 (his4-519, URA3). The LEU2 probe was made from a $2.3-\mathrm{kb}$ SalI-XhoI fragment from YEpl3 (Broach et al. 1979). The lacZ probe was from a $3.0-\mathrm{kb}$ BamHI fragment from pMC1871 (Shapira et al. 1983). All other hybridization probes are described by Herrick et al. (1990).

\section{Strain construction}

The alleles designated upf1- $\Delta 1$ and upf1- $\Delta 2$ are chromosomal deletions of UPF1 constructed by substituting a 1.1-kb DNA fragment containing URA 3 for UPF1 sequences. The deletion in upf $1-\Delta 1$ includes the $5^{\prime}$ three-fifths of the UPF1 open reading frame and 187 nucleotides of the $5^{\prime}$-untranslated region. The deletion in upf $1-\Delta 2$ has the same $5^{\prime}$ end point but includes the entire UPF1 translated region and 189 nucleotides of the $3^{\prime}$ untranslated region. Both deletions confer the same recessive phenotype as the original upf1- $\Delta 2$ allele (Leeds 1991).

Strain PLY36A was constructed as follows. Plasmid pMM54 (suf $1^{+}$, URA3; Mendenhall et al. 1987) was linearized by digestion with BgIII, which cuts in the suf $1^{+}$-flanking region, and used to transform strain PLY36 (Table 1). $\mathrm{Ura}^{+}$transformants all contained the chromosomal copy of SUF1-1 and were therefore $\mathrm{His}^{+}$at $30^{\circ} \mathrm{C}$ due to suppression of his4-38. One transformant, containing a copy of pMM54 stably integrated at the SUF1 locus, was plated on media containing 5-fluoro-orotic acid to select for Ura ${ }^{-}$colonies (Boeke et al. 1984). These colonies were then screened for loss of SUF1-1, which results in a His ${ }^{-}$ phenotype. The loss of SUF1-1 in one of these strains, denoted PLY36A, was confirmed by crossing it to a suf $1^{+}$his4-38 strain and verifying that the resulting tetrads contained only His spores.

Both PLY36 and PLY36A carry the recessive allele upf1-2. $U P F 1^{+}$derivatives of these two strains were constructed by transforming them with YCpPL63 $\left(U P F 1^{+}, U R A 3^{+}\right)$. upf1-2 derivatives were obtained by transforming with the vector $\mathrm{YCp} 50$ $\left(U R A 3^{+}\right)$.

Strains PLY149, PLY150, and PLY171 were constructed as follows. Plasmids YRpPL14, YRpPL15, and YRpPL81 each contain a his 4 : lacZ fusion gene. Strain PLY102 was transformed with these plasmids after each was linearized by digestion with BglII, which cuts in the TRP1-flanking region. Transformants carrying YRpPL14, YRpPL15, and YRpPL81 were designated PLY149, PLY150, and PLY171, respectively (Table 1). Tetrad analysis showed that in each case the plasmid had integrated into the chromosome and the site of integration was linked tightly to the trp1 locus. This was confirmed by Southern hybridization analysis with lacZ DNA as a probe, which also verified that a single copy of each plasmid was present in the chromosome. The linker used in the construction of the his438,-UAA : IacZ allele in YRpPL81 contains a HpaI site that can be detected in strain PLY171 by Southern analysis. Hybridization of our HIS4 probe to HpaI-digested genomic DNA from strain PLY150 yields a $3.8-\mathrm{kb}$ restriction fragment from the integrated his4-38: lacZ fusion allele. Hybridization of the same probe to HpaI-digested DNA from strain PLY171 yields a 2.9-kb and an $0.9-\mathrm{kb}$ restriction fragment, which are the sizes expected to result from $\mathrm{HpaI}$ cleavage within the linker.

Strains PLY149, PLY150, and PLY171 each carry the recessive allele upf1- $\Delta 1$. UPF ${ }^{+}$derivatives of these strains were constructed by transforming them with YEpPL55 (UPF1 $\left.{ }^{+}, L E U 2^{+}\right)$. upf1- $\Delta 1$ derivatives were obtained by transforming with the vector YEp13 $\left(L E U 2^{+}\right)$.

The strains used to measure mRNA decay rates all carry rpb1-1 and either upf1- $\Delta 1$ or upf1- $\Delta 2$ (Table 1). UPF $1^{+}$derivatives of these strains were constructed by transforming them with either YCpPL53 (UPF $\left.1^{+}, T R P 1^{+}\right)$or YEpPL55 (UPF1 ${ }^{+}$, $L E U 2^{+}$). upf1 ${ }^{-}$derivatives were obtained by transforming with either YCpMS38 $\left(T R P 1^{+}\right)$or YEp13 $\left(\right.$LEU2 $\left.{ }^{+}\right)$.

\section{$m R N A$ decay rates}

Decay rates of individual mRNAs were measured by the methods of Herrick et al. (1990) and Parker et al. (1991). Cultures of strains carrying the temperature-sensitive polymerase II allele $r p b 1-1$ were shifted rapidly from $25^{\circ} \mathrm{C}$ to $36^{\circ} \mathrm{C}$ by the addition of an equal volume of media heated to $48^{\circ} \mathrm{C}$. Aliquots of cells were removed at specific times and spun down, and the cell pellets were frozen in dry ice/ethanol. RNA was prepared and fractionated on denaturing $1 \%$ agarose gels, transferred to nitrocellulose, and hybridized to radiolabeled DNA probes. The absolute amount of radiolabeled probe hybridized to specific bands was quantitated on a Betascope Blot Analyzer (Betagen, Waltham, MA). Cricket graph (Cricket Software, Malvern, PA) was used to generate mRNA decay curves, which were plotted as the log of the percentage of activity remaining in a particular band (relative to the activity at time zero/ versus time at $36^{\circ} \mathrm{C}$. Lines were 
generated by using a least-squares fit. As noted previously (Herrick et al. 1990; Parker et al. 1991|, decay curves of some transcripts were biphasic, with a second, slower-decaying component comprising $5 \%-20 \%$ of the total RNA. Although the cause of the biphasic decay is unclear, the small amount of slow component is, in all cases, insufficient to make a significant contribution to the overall decay rate.

Decay rates in strain PLY150 were measured by inhibiting transcription with the drug thiolutin $(3 \mu \mathrm{g} / \mathrm{ml})$ (Herrick et al. 1990; Parker et al. 1991). Time points were taken following addition of the drug and analyzed as described above.

\section{Protein isolation and Western blots}

Cell pellets containing $\sim 10^{9}$ cells were washed once with lysis buffer $[50 \mathrm{~mm}$ Tris- $\mathrm{HCl}(\mathrm{pH} 7.4), 0.25 \mathrm{M} \mathrm{NaCl}, 0.1 \%$ (vol/vol) NP-40, $5 \mathrm{~mm}$ EDTA] and resuspended in $1.6 \mathrm{ml}$ of lysis buffer containing $1.0 \mathrm{~mm}$ phenylmethylsulfonyl fluoride and $1.0 \mathrm{mg} /$ liter each of chymostatin, leupeptin, pepstatin, antipain, and aprotinin. The cells were transferred to two $1.5-\mathrm{ml}$ tubes that were then filled to the top with cold, acid-washed glass beads

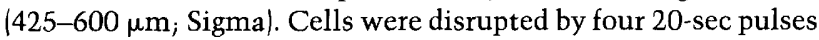
on a Mini-Beadbeater (Biospec Products, Inc.). Protein concentrations in the supernatant were quantitated by absorbance at $280 \mathrm{~nm}$ and equal amounts from each strain were separated by SDS-PAGE. Following transfer of proteins to nitrocellulose (Towbin et al. 1979), immunoblotting was performed as described by BRL (Immunoselect instruction manual, no. 9590SA) with mouse anti- $\beta$-galactosidase and alkaline phosphatase coupled to anti-mouse IgG.

\section{Polyribosome analysis}

Polyribosomes were prepared and fractionated as described by Hutchison (1969) and Sachs and Davis (1989). The experiment involved comparison of profiles obtained from different sucrose gradients. We found that variation between gradients, as measured by UV monitoring, was minimized by preparing the gradients according to the method of Luthe (1983). Fractions were extracted three times with phenol/chloroform and ethanol-precipitated. The pellet was resuspended in water, and half of each fraction was loaded on denaturing $1 \%$ agarose gels, transferred to nitrocellulose, and hybridized to radiolabeled DNA probes. The activity of individual bands was measured with a Betascope Blot Analyzer (Betagen, Waltham, MA).

\section{$\beta$-Galactosidase assays}

Activity was quantitated by using the whole-cell ONPG assay of Miller (1972) as modified by Guarente (1981). Qualitative $\mathrm{X}$-gal assays were done by the method of Breeden and Nasmyth (1985).

\section{Acknowledgments}

This research was supported by the College of Agricultural and Life Sciences, University of Wisconsin, Madison, WI, U.S. Public Health Service (P.H.S.) grants GM26217 (M.R.C.) and GM27757 (A.J.), American Cancer Society postdoctoral fellowship PF3410 (S.W.P.), and P.H.S. training grant in genetics GM07133 (P.L.). This is paper no. 3178 of the University of Wisconsin Laboratory of Genetics.

The publication costs of this article were defrayed in part by payment of page charges. This article must therefore be hereby marked "advertisement" in accordance with 18 USC section 1734 solely to indicate this fact.

\section{References}

Andreadis, A., Y. -P. Hsu, M. Hermodson, G. Kohlhaw, and P. Schimmel. 1984. Yeast LEU2: Repression of mRNA levels by leucine and primary structure of the gene product. J. Biol. Chem. 259: 8059-8062.

Barker, G.F. and K. Beemon. 1991. Nonsense codons within the Rous sarcoma virus gag gene decrease the stability of unspliced viral RNA. Mol. Cell. Biol. 11: 2760-2768.

Birnboim, H.C. and J. Doly. 1979. A rapid alkaline extraction procedure for screening recombinant plasmid DNA. Nucleic Acids Res. 7: 1513-1523.

Boeke, J.D., F. Lacroute, and G.R. Fink. 1984. A positive selection for mutants lacking orotidine-5'-phosphate decarboxylase activity in yeast: 5-Fluoro-orotic acid resistance. Mol. Gen. Genet. 197: 345-346.

Breeden, L. and K. Nasmyth. 1985. Regulation of the yeast $H O$ gene. Cold Spring Harbor Symp. Quant. Biol. 50: 643-650.

Broach, J.R., I.N. Strathern, and J.B. Hicks. 1979. Transformation in yeast: Development of a hybrid cloning vector and isolation of the CAN1 gene. Gene 8: 121-133.

Brown, A.J.P. 1989. Messenger RNA stability in yeast. Yeast 5: 239-257.

Casadaban, M.J., A. Martinez-Arias, S.K. Shapira, and J. Chou. 1983. $\beta$-Galactosidase gene fusions for analyzing gene expression in Escherichia coli and yeast. Methods Enzymol. 100: $293-308$.

Cheng, J., M. Fogel-Petrovic, and L.E. Maquat: 1990. Translation to near the distal end of the penultimate exon is required for normal levels of spliced triosephosphate isomerase mRNA. Mol. Cell. Biol. 10: 5215-5225.

Culbertson, M.R., K.M. Underbrink, and G.R. Fink. 1980. Frameshift suppression in Saccharomyces cerevisiae. II. Genetic properties of Group II suppressors. Genetics 95: 833853.

Donahue, T.F., P.J. Farabaugh, and G.R. Fink. 1981. Suppressible glycine and proline four base codons. Science 212: 455 457.

- 1982. The nucleotide sequence of the HIS4 region of yeast. Gene 18: 47-59.

Fink, G.R. and C.A. Styles. 1974. Gene conversion of deletions in the HIS4 region of yeast. Genetics 77: 231-244.

Gaber, R.F. and M.R. Culbertson. 1982. Frameshift suppression in Saccharomyces cerevisiae. IV. New suppressors among spontaneous co-revertants of the Group-II his4-206 and leu2-3 frameshift mutations. Genetics 101: 345-367.

- 1984. Codon recognition during frameshift suppression in Saccharomyces cerevisiae. Mol. Cell. Biol. 4: 2052-2061.

Guarente, L. 1981. Yeast promoters and lacZ fusions designed to study expression of cloned genes in yeast. Methods Enzymol. 101: 181-191.

Herrick, D., R. Parker, and A. Jacobson. 1990. Identification and comparison of stable and unstable mRNAs in Saccharomyces cerevisiae. Mol. Cell. Biol. 10: 2269-2284.

Holmes, D.S. and M. Quigley. 1981. A rapid boiling method for the preparation of bacterial plasmids. Anal. Biochem. 114: 193-197.

Humphries, R.K., T.J. Ley, N.P. Anagnou, A.W. Baur, and A.W. Nienhuis. 1984. $\beta^{\circ}$-Thalassemia gene: A premature termination codon causes $\beta$-mRNA deficiency without affecting cytoplasmic $\beta$-mRNA stability. Blood 64: 23-32.

Hutchison, H.T., L.H. Hartwell, and C.S. McLaughlin. 1969. 
Temperature-sensitive yeast mutant defective in ribonucleic acid production. J. Bacteriol. 99: 807-814.

Ito, H., Y. Fukuda, K. Murata, and A. Kimura. 1983. Transformation of intact yeast cells treated with alkali cations. $J$. Bacteriol. 153: 163-168.

Leeds, P. 1991. "Genetic analysis and characterization of UPF1: A yeast gene that affects mRNA stability, "Ph.D. thesis. University of Wisconsin, Madison, WI.

Lindquist, S. 1981. Regulation of protein synthesis during heat shock. Nature 293: 311-314.

Losson, R. and F. Lacroute. 1979. Interference of nonsense mutations with eukaryotic messenger RNA stability. Proc. Natl. Acad. Sci. 76: 5134-5137.

Losson, R., R.P.P. Fuchs, and F. Lacroute. 1983. In vivo transcription of a eukaryotic regulatory gene. EMBO /. 2: 2179 2184.

Luthe, D.S.. 1983. A simple technique for the preparation and storage of sucrose gradients. Anal. Biochem. 135: 230-232.

Maquat, L.E., A.J. Kinniburgh, E.A. Rachmilewitz, and J. Ross. 1981. Unstable $\beta$-globin mRNA in mRNA-deficient $\beta^{\circ}$ thalassemia. Cell 27: 543-553.

Mendenhall, M.D., P. Leeds, H. Fen, L. Mathison, M. Zwick, C. Sleiziz, and M.R. Culbertson. 1987. Frameshift suppressor mutations affecting the major glycine transfer RNAs of Saccharomyces cerevisiae. I. Mol. Biol. 194: 41-58.

Miller, J.H. 1972. Experiments in molecular genetics. Cold Spring Harbor Laboratory, Cold Spring Harbor, New York.

Nonet, M., C. Scafe, J. Sexton, and R. Young. 1987. Eucaryotic RNA polymerase conditional mutant that rapidly ceases mRNA synthesis. Mol. Cell. Biol. 7: 1602-1611.

Parker, R. and A. Jacobson. 1990. Translation and a 42-nucleotide segment within the coding region of the mRNA encoded by the Mat $\alpha 1$ gene are involved in promoting rapid mRNA decay in yeast. Proc. Natl. Acad. Sci. 87: 2780-2784.

Parker, R., D. Herrick, S.W. Peltz, and A. Jacobson. 1991. Measurement of mRNA decay rates in Saccharomyces cerevisiae. Methods Enzymol. 194: 415-423.

Peltz, S.W., G. Brewer, P. Bernstein, P.A. Hart, and J. Ross. 1990. Regulation of mRNA turnover in eukaryotic cells. Crit. Rev. Eukaryotic Gene Exp. 1: 99-126.

Rose, M.D., P. Novick, J.H. Thomas, D. Botstein, and G.R. Fink. 1987. A Saccharomyces cerevisiae genomic plasmid bank based on a centromere-containing shuttle vector. Gene 60: $237-243$.

Sachs, A.B. and R.W. Davis. 1989. The poly(A) binding protein is required for poly(A) shortening and 60 s ribosomal subunitdependent translation initiation. Cell 58: 857-867.

Sandbaken, M.G. and M.R. Culbertson. 1988. Mutations in elongation factor EF1- $\alpha$ affect the frequency of frameshifting and amino acid misincorporation in Saccharomyces cerevisiae. Genetics 120: $923-934$.

Sanger, F., S. Nicklen, and A.R. Coulson. 1977. DNA sequencing with chain terminating inhibitors. Proc. Natl. Acad. Sci. 74: 5463-5467.

Shapira, S.K., J. Chou, F.V. Richaud, and M.J. Casadaban. 1983. New versatile plasmid vectors for expression of hybrid proteins coded by a cloned gene fused to $l a c Z$ gene sequences encoding an enzymatically active carboxy-terminal portion of $\beta$-galactosidase. Gene 25: 71-82.

Sherman, F., G.R. Fink, and C.W. Lawrence. 1979. Methods in yeast genetics. Cold Spring Harbor Laboratory, Cold Spring Harbor, New York.

Takeshita, K., B.G. Forget, A. Scarpa, and E.J. Benz. 1984. Intranuclear defect in $\beta$-globin mRNA accumulation due to a premature translation termination codon. Blood 64: 13-22.

Towbin, H., T. Staehelin, and J. Gordon. 1979. Electrophoretic transfer of proteins from polyacrylamide gels to nitrocellulose sheets: Procedure and some applications. Proc. Natl. Acad. Sci. 76: 4350-4354.

Urlaub, G., P.J. Mitchell, C.J. Ciudad, and L.A. Chasin. 1989. Nonsense mutations in the dihydrofolate reductase gene affect RNA processing. Mol. Cell. Biol. 9: 2868-2880.

Yanisch-Perron, C., J. Vieira, and J. Messing. 1985. Improved M13 phage cloning vectors and host strains: Nucleotide sequences of the M13mp18 and pUC19 vectors. Gene 33: 103119. 


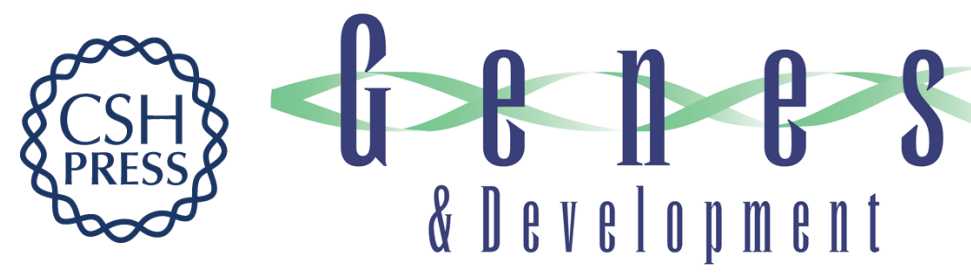

\section{The product of the yeast UPF1 gene is required for rapid turnover of mRNAs containing a premature translational termination codon.}

P Leeds, S W Peltz, A Jacobson, et al.

Genes Dev. 1991, 5:

Access the most recent version at doi:10.1101/gad.5.12a.2303

References This article cites 40 articles, 21 of which can be accessed free at:

http://genesdev.cshlp.org/content/5/12a/2303.full.html\#ref-list-1

License

Email Alerting

Service

Receive free email alerts when new articles cite this article - sign up in the box at the top right corner of the article or click here.

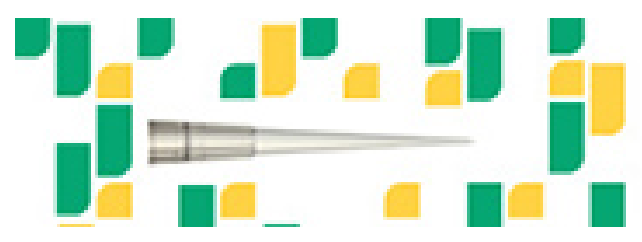

Focused on your science. 